\title{
La tragedia de los comunes revisitada: de la teoría formal a las formas históricas de desposesión \author{
forms of dispossession
} \\ Revisiting the tragedy of the commons: from formal theory to the historical
}

\section{Matías L. Saidel}

\author{
Matías L. Saidel es investigador del Consejo Nacional \\ de Investigaciones Científicas y Técnicas y docente de \\ la Universidad Católica de Santa Fe y de la Universidad \\ Nacional de Entre Ríos, Argentina. \\ E-mail: msaidel@ucsf.edu.ar
}

\section{resumen}

En este trabajo haremos referencia primero a la noción de tragedia de los comunes en la óptica de Hardin, según la cual los bienes comunes se hallan condenados a una sobreapropiación y depredación por parte de individuos racionales y autointeresados. Luego, comentaremos la refutación de la teoría de Hardin en sus propios términos por parte de Feeny, Ostrom y otros y nos referiremos a algunos de los modos de entender a los comunes hoy, más allá del marco de elección racional en el que fueran inicialmente considerados. Posteriormente, llevaremos dicha tragedia del plano de la teoría formal al de una teoría que tome en cuenta las relaciones de dominación que han hecho posible la privatización de los comunes, revisitando la noción de acumulación originaria. Para concluir, sostendremos que lo común debe ser entendido como un principio de acción política que conlleva responsabilidades y normas ajenas a las del capitalismo neoliberal, bajo cuyo imperio el planeta se dirige a una catástrofe ecológica, económica y civilizatoria.

\section{palabras clave}

tragedia de los comunes / bienes comunes / acumulación por desposesión / comunes / neoliberalismo

\section{summary}

In this paper we will comment on the notion of tragedy of the commons as developed by Hardin, according to which common goods are doomed to over-appropriation and depletion by rational and self-interested individuals. Then, we will delve on the refutation of Hardin's theory in its own terms by Feeny, Ostrom and others, and we will explore some of the ways to understand todays' commons, beyond the framework of rational choice in which they were considered at the beginning. Later, we will take the idea of tragedy from formal theory to another one that takes into account relations of domination that made possible the privatization of the commons, revisiting the notion of primitive accumulation. To conclude, we will maintain that the common must be understood as a principle of political action that carries norms and responsibilities alien to those of neoliberal capitalism, under which rule the planet runs towards an ecological, economic and civilizational catastrophe.

\section{keywords}

tragedy of the commons / common goods / accumulation by dispossession / commons / neoliberalism 


\section{La tragedia de los comunes como explicación teórica}

Como se ha repetido frecuentemente, la noción de tragedia de los comunes fue introducida en el mundo académico por el biólogo neomalthusiano Garrett Hardin en un artículo de 1968, donde sostenía que el problema de la superpoblación entraba en la categoría de aquellos que no tienen una solución técnica, en la medida en que, como observara Malthus un siglo antes, la población crece exponencialmente y no sucede lo mismo con los alimentos en un mundo finito como el nuestro. Para Hardin, la mano invisible de Adam Smith -la idea de que persiguiendo el propio interés se contribuye al bienestar general- quedaba refutada en lo referente al control poblacional ya en un texto de 1833, escrito por el matemático W. Forster Lloyd. Desde un enfoque marginalista, Hardin explica que la tragedia de los bienes comunes consiste en que, en una situación de libre acceso a éstos, la decisión racional de cada actor sería la de utilizar el recurso común tanto como sea posible en detrimento de los demás usuarios, con lo cual inevitablemente el recurso ( $v$. $g r$ tierras comunes, recursos marítimos, el aire puro, los parques nacionales, la seguridad social) terminaría siendo depredado. ${ }^{1}$ Usando la metáfora del pastoreo de ovejas, Hardin muestra que cada unidad añadida por un propietario a un terreno común implica un costo proporcional muy inferior al beneficio que obtiene, pues los costos son soportados por todos y el beneficio es exclusivo para él. En ese marco, cada actor racional va a buscar sobreapropiarse del recurso, llevando a al agotamiento de dicho recurso. "Y ahí está la tragedia. Cada hombre está encerrado en un sistema que lo impulsa a incrementar su ganado ilimitadamente, en un mundo limitado" (Hardin, 1995 [1968]).

De ahí la sentenciosa conclusión a la que llega el biólogo generalizando el ejemplo anterior:

La ruina es el destino hacia el cual corren todos los hombres, cada uno buscando su mejor provecho en un mundo que cree en la libertad de los recursos comunes. La libertad de los recursos comunes resulta [en] la ruina para todos (Hardin, 1995 [1968]).

Para Hardin, dicha lógica se extendería a los distintos bienes comunes de la humanidad en la medida en que no estén regulados, como la contaminación del aire y la tierra, la reproducción biológica, etc. En estos casos, la mano invisible y el autointerés, lejos de llevar a un mejor resultado colectivo, terminarían por agotar el recurso común o por conducir a una situación insostenible. La teoría de Hardin se asemeja así al dilema del prisionero (posteriormente analizado por Ostrom, 2011 [1990]), donde el desconocimiento de la estrategia de los demás actores lleva en general a tomar la decisión cuyo resultado es el peor posible tanto individual como colectivamente Para Hardin, la única solución viable para conservar los bienes comunes era poner barreras de acceso al bien en cuestión, haciéndolo propiedad pública o privada. Así, por ejemplo, un propietario privado no depredaría su propio bosque o prado y se encargaría de evitar que otros lo hagan, del mismo modo que una gestión pública tendría la capacidad de imponer sanciones a los infractores. $^{2}$ En ese marco, Hardin sugiere la necesidad de leyes coercitivas o incentivos 
fiscales para, por ejemplo, evitar la contaminación del agua y el aire, pues estos no son problemas que se puedan resolver con un llamado a la toma de conciencia. De allí que lo óptimo sería lograr una "coerción mutua, mutuamente acordada por la mayoría de las personas afectadas" (1995 [1968]). Una década más tarde, Hardin sostendría que para solucionar el dilema de los bienes comunes era necesario o bien un sistema empresarial privado o bien el socialismo, un Leviatán que ejerciera una coerción externa para dar solución a los problemas ecológicos y demográficos (1978).

A pesar del rol que le otorga Hardin a la intervención pública en la protección de los bienes comunes, su teoría, junto con la de otros autores que siguieron su línea, fue retomada con frecuencia para criticar cualquier forma de propiedad colectiva a favor de la propiedad individual y exclusiva, que la economía política, de los fisiócratas a los neoliberales, entiende como la más eficiente económica y socialmente (Orsi, 2015). Esto puede explicarse en parte por el contexto de recepción de las ideas de Hardin, donde el Estado de Bienestar (desarrollado en el primer mundo e incipiente en el tercero) y la gestión pública de los bienes comunes que aseguran la reproducción de la vida en nuestras sociedades (petróleo, gas, agua, telecomunicaciones, energía, salud, educación, etc.) eran sometidos a distintas presiones que terminaron por dar lugar a una ola de privatizaciones masivas, bajo el pretexto de la eficiencia económica.

No obstante, a pesar del triunfo político-ideológico del neoliberalismo y de la creciente privatización de los bienes comunes, el diagnóstico de Hardin fue rebatido con sólidos argumentos teóricos y demostraciones empíricas en las últimas tres décadas. Por ejemplo, en 1986, Carol Rose escribe "La comedia de los comunes", señalando que entre la propiedad pública y la privada habría una "propiedad inherentemente pública", poseída y gestionada colectivamente por la sociedad en su conjunto y que ha servido para expandir la riqueza y la sociabilidad. ${ }^{3}$ De cualquier manera, el verdadero quiebre teórico y analítico se produce cuando, por un lado, se pasa de considerar propiedades que serían inherentes a los comunes a evaluar los modos de gestión o gobierno de éstos y, por el otro, cuando se introducen dimensiones socio-históricas en el análisis.

\section{De la tragedia al gobierno de los bienes comunes}

El modelo de elección racional de Hardin tiene la virtud de ofrecer una explicación teórica plausible y aplicable a casos distintos. Sin embargo, en su pretensión de universalidad explicativa peca de excesivo formalismo, pues no tiene en cuenta las especificidades históricas, los acuerdos institucionales y las subjetividades que deben gestionar los recursos compartidos, reduciéndolas a las de un sujeto ahistórico, racional y autointeresado. En efecto, la explicación de Hardin asume como algo natural el comportamiento egoísta y calculador que llevaría a la depredación de los bienes comunes, cuando este es producto de condiciones históricas e institucionales específicas y cuando la observación empírica de la gestión de los comunes se encarga de desmentir repetidamente dichos supuestos. En ese sentido, los trabajos de Ostrom y otros teóricos cercanos a su escuela resultarán fundamentales 
al mostrar que, si se pasa de la teoría formal a los estudios de los comunes reales, se llega a resultados muy distintos de los de Hardin.

En un artículo de 1990, Feeny et al. sostenían que, a diferencia de lo que suponía Hardin, hay abundante evidencia de la capacidad de grupos sociales para diseñar, utilizar y adaptar mecanismos ingeniosos de derechos de uso entre sus miembros. De hecho, los comunes ingleses, como otros históricos y actuales, estaban frecuentemente sujetos a sistemas de regulación comprehensivos, tanto de las cabezas de ganado que podían pastar como de quiénes y cuándo tenían derecho a hacerlo. Por eso mismo, una gran cantidad de estudiosos señalaron que los comunes operaron de manera exitosa durante cientos de años en la Inglaterra medieval y cuestionaron que una tragedia de los comunes, como la que describe Hardin, haya tenido lugar (Feeny et al., 1990). Por el contrario, los casos estudiados muestran que la gente es capaz de organizar y monitorear el uso de recursos de manera de hacerlos sustentables y que, por tanto, la acción colectiva es posible y efectiva. Para Feeny, el problema del argumento de Hardin es que ignora el rol de los arreglos institucionales que hacen posible la exclusión y la regulación del uso, como así también los factores culturales y las interacciones sociales. Por ello, su modelo resulta demasiado simplificado y determinista y se haría necesaria una teoría más comprehensiva de los recursos de propiedad común que diera cuenta del manejo sustentable de los recursos.

En ese marco, Feeny et al. (1990) recuperan el rol de la propiedad comunal, junto a la privada y la pública, y señalan la necesidad de introducir los arreglos institucionales y los factores culturales en el análisis, para mejorar la capacidad de comprensión y predicción de este tipo de fenómenos. Al igual que Elinor Ostrom, definen allí a los recursos de propiedad común (o de uso compartido [RUC] en Ostrom) como una clase de recursos para los cuales la exclusión es difícil y el uso compartido incluye sustractibilidad o rivalidad (Berkes et al. apud Feeny et al., 1990; Dolsak y Ostrom, 2003). Dicho de manera sintética: los RUC son bienes no exclusivos y rivales. Que sean rivales quiere decir que lo que una persona retira o deposita en un recurso reduce la capacidad de otros de hacer lo mismo, lo que da lugar a la posibilidad de sobreutilización, congestión o destrucción del recurso. $\mathrm{Al}$ igual que lo que sucede con los bienes públicos, los potenciales beneficiarios enfrentan la tentación de comportarse como free riders. De allí la necesidad de instituciones adecuadas que eviten dicho comportamiento (Dolsak y Ostrom, 2003). Precisamente por eso, al igual que Ostrom, Feeny et al. reconocen la importancia de la distinción entre la naturaleza intrínseca del recurso y el régimen de derechos de propiedad bajo el cual es mantenido, que pueden ser cuatro: acceso abierto, propiedad privada, propiedad comunal y propiedad estatal (Feeny et al., 1990). Los autores definen: 1) el acceso abierto como la ausencia de derechos de propiedad bien definidos, donde el acceso al recurso no está regulado y es libre y abierto a todos. 2) La propiedad privada implica el derecho de excluir a otros del uso del recurso. Son derechos generalmente protegidos por el Estado, exclusivos y transferibles. 3) La propiedad comunal implica que el recurso es mantenido por una comunidad de usuarios interdependientes que regulan el uso y excluyen a quienes 
no pertenecen a ella. Dentro de la comunidad, los derechos al recurso son en general de igual acceso y uso. En muchos casos, se llama a este tipo propiedad común o, simplemente, un común (a commons). 4) Finalmente, la propiedad pública deja los derechos al recurso en manos del Estado, que decide sobre el acceso al recurso y los modos y niveles de explotación, detentando poderes coercitivos para implementarlos (Feeny et al., 1990). Como vemos, los ejemplos de un pastizal abierto o de la contaminación ambiental, que para Hardin llevan a la tragedia de los comunes, se corresponderían, desde el punto de vista de las formas de propiedad, con las situaciones de acceso abierto y no con la propiedad comunal.

Esto queda de manifiesto en El gobierno de los bienes comunes (2011 [1990]), texto en que el quiebre analítico en el estudio de los comunes se materializa de manera palmaria. Ostrom analiza decenas de casos de comunes en todo el mundo que abarcan un lapso de un milenio. En base a ello, sostiene que la tragedia de los comunes puede ser y ha sido evitada con frecuencia gracias a soluciones colectivas de los problemas que refieren a los recursos comunes, con la elaboración de sistemas institucionales de distinta índole, cuyo diseño busca asegurar la sustentabilidad y eficiencia en la administración de recursos en un ambiente legal y regulatorio dado (Dolsak y Ostrom, 2003).

Al igual que Hardin, Ostrom se vale de supuestos de elección racional para abordar el manejo de los bienes comunes. Sin embargo, la teoría que desarrolla Ostrom, en base a sus estudios empíricos, ya no da por supuesto ni que el autointerés racional se aplique a todos los casos, ni que cuando este existe se traduzca en una competencia egoísta y de corto plazo, precisamente porque, a diferencia de Hardin, Ostrom tiene en cuenta los arreglos institucionales que hacen que los bienes comunes sean preservados y administrados de manera conjunta. En ese caso, el mínimo denominador del interés común sería que el recurso compartido se mantenga en el tiempo y, en lo posible, que sea mejorado y/o incrementado.

En efecto, en su ensayo de 1990, Ostrom considera tres modelos influyentes para abordar el problema de los bienes comunes: el de Hardin, el del juego del dilema del prisionero y el de la lógica de la acción colectiva de Mancur Olson. Los tres parten del supuesto de que los individuos son racionales y autointeresados, y ponen en el centro el problema del free rider: alguien que puede gozar de los beneficios de un bien colectivo y que no tiene incentivos para contribuir a su mantenimiento o suministro. Asimismo, los tres muestran que individuos perfectamente racionales pueden llegar a resultados "irracionales" a la vista de quienes participan (2011 [1990]: 43).

Sin embargo, lo que vale para estos juegos formales, donde los actores se ven llevados a desconfiar de los demás, no se verifica en el caso de los comunes. Los análisis de Ostrom muestran que Hardin se equivocaba al plantear una situación de libre acceso a los comunes, donde se asume poca o nula comunicación, y donde la gente actúa sólo en su auto-interés inmediato, proponiendo así como alternativa la privatización o la intervención del gobierno (Hess y Ostrom, 2006: 11). Por un lado, Ostrom recuerda que dicha alternativa no es dicotómica, ya que hay un tercero excluido en esa lógica. Es decir, en primer lugar, que -como lo saben muy 
bien los teóricos neoliberales- incluso un mercado competitivo es un bien público y no puede existir sin instituciones que lo mantengan. "En escenarios de campo (...) las instituciones públicas y privadas con frecuencia están entretejidas y dependen una de la otra" (2011: 56). Por otro lado, un juego posible que no estaba siendo considerado por los sostenedores del Leviatán y/o del mercado como únicos gestores posibles de los bienes comunes es aquel donde "los pastores mismos pueden establecer un contrato vinculante para comprometerse con una estrategia de cooperación que ellos mismos forjarán" (2011: 56). En este tipo de juego, "los participantes mismos diseñan sus propios contratos a la luz de la información que tienen a la mano" (2011: 59). Hay muchos grupos que pueden administrar y mantener efectivamente recursos comunes si tienen condiciones adecuadas, como reglas apropiadas, buenos mecanismos de resolución de conflictos y barreras grupales bien definidas (Hess y Ostrom, 2006: 11). En este sentido, los experimentos de Ostrom muestran que lo único que se corrobora de la teoría estándar es que cuando los apropiadores no se comunican entre sí (como en el modelo de Hardin) tienden a sobreapropiarse del recurso en cuestión. Más allá de las reglas particulares que funcionan en cada caso, Ostrom sostiene que la diferencia la hacen los principios generales que subyacen a dichas reglas:

El hecho importante es que los usuarios locales tengan acuerdos sobre las reglas de definición de límites, los mecanismos de solución de conflictos, los planes de monitoreo, las sanciones graduadas apropiadas y sus propias reglas relacionadas con otros principios de diseño (2011: 13).

En efecto, para sostener exitosamente los recursos de uso compartido son determinantes tanto las instituciones como las tecnologías disponibles. A partir de los estudios empíricos, Ostrom releva determinadas características que conducen con mayor probabilidad a una gobernanza exitosa de estos recursos: pequeño tamaño, fronteras estables y bien definidas, pocas externalidades negativas por el uso del recurso, capacidad de los usuarios de monitorear stocks y flujos, nivel moderado de uso del recurso y dinámicas del recurso bien entendidas por sus usuarios (Dolsak y Ostrom, 2003: 12-13). Asimismo, son determinantes las características de los apropiadores, como su número, heterogeneidad, confianza, duración, cantidad de temas compartidos, etc. (2003: 17).

Por todo lo dicho, queda claro que existen varios problemas con la teoría de Hardin, pues su modelo formal no se condice con lo que se ha observado empíricamente y, por lo tanto, es el propio Hardin el que debería probar lo que afirma. En ese marco, Hardin no sólo habla de sujetos racionales y autointeresados abstractos, sino que tiende a confundir los recursos de uso compartido con el libre acceso y supone una ausencia de comunicación entre los actores, algo que no se condice con la situación efectiva de los comunes, que son precisamente instituciones establecidas para lograr acuerdos entre las partes y "prevenir el riesgo de sobreexplotación" (Dardot y Laval, 2015: 168). Por lo demás, si bien Hardin acierta en señalar la dificultad de regular los recursos donde hay acceso abierto, en muchos casos la tragedia ocurre sólo después de que las condiciones de acceso 
abierto hayan sido creadas, frecuentemente como consecuencia de la destrucción de sistemas comunales preexistentes de posesión de tierras y de recursos marítimos (Feeny et al., 1990: 6). En ese sentido, tanto Ostrom como Feeny y otros analizan, desde fines de los años ' 80 , casos de pueblos que fueran propietarios y administradores de los bosques comunales por generaciones, en los que la nacionalización equivalió a una expropiación y, como consecuencia de la incapacidad de esos Estados de controlar el recurso, "la nacionalización creó una situación de acceso abierto ahí donde antes había un acceso limitado a los recursos de propiedad común" (2011: 68).

Pero esto no es todo: como señala Harvey, por un lado, si bien la teoría de Hardin fue leída como un argumento acerca de la eficiencia de la propiedad privada, lo cierto es que la metáfora de los pastores no funcionaría si el ganado hubiese sido poseído en común. "Sería claro entonces que era la propiedad privada en ganado y el comportamiento de maximización de la utilidad individual los que están en el centro del problema" (Harvey, 2011). Por otro lado, Hardin proyecta ilegítimamente un ejemplo de una escala a otra totalmente distinta, utilizando el ejemplo del pastoreo de ovejas para pensar el problema de la superpoblación. Este problema de escalas está presente en los análisis de Ostrom, puesto que, si a nivel local se pueden poseer y gestionar los recursos en común, al pasar a una escala global parecen necesarias instituciones jerárquicas de toma de decisiones. Por eso las formas de preservación y gestión de los comunes deben ser analizadas en cada caso y están sujetas al conflicto político. Como señalan Dardot y Laval, el acento puesto en el establecimiento colectivo de reglas de acción práctica "introduce una concepción gubernamental de los comunes, entendidos como sistemas institucionales de incitación a la cooperación" (2015: 170). En este sentido, debemos subrayar nuevamente que no es la naturaleza intrínseca del recurso la que lo hace abierto, común o privado, sino las reglas institucionales que se establecen para el manejo de dichos recursos. Esto vale tanto para los bienes naturales como para los comunes del conocimiento, sobre los que ahora nos detendremos.

\section{2. b. Bienes comunes intelectuales}

La puesta en entredicho de la tragedia de los comunes se dio en el mismo momento histórico en el que, por un lado, se hacían grandes avances en el terreno de las tecnologías de la información y, por otro, se expandían las privatizaciones a nuevos sectores, a través de la legislación referente a la propiedad intelectual. Eso posibilitó que lo que hasta entonces parecía inapropiable, como el conocimiento compartido, la información, los códigos genéticos, etc. pudiese ser apropiado, privatizado a través de distintas formas de propiedad intelectual, que van de las patentes industriales tradicionales a los derechos de copyright. De allí que en ese contexto se haya desarrollado la idea de que se asistía a una segunda ola de cercamientos (vid infra) que ya no abarcaba sólo los bienes naturales o materiales, sino también los bienes inmateriales, como el conocimiento y las creaciones culturales. En ese marco surge el movimiento por el software libre y el acceso abierto, que va a tener varias coincidencias teóricas con los estudios sobre los comunes de Ostrom. 
Un elemento clave que distingue a los bienes comunes materiales de los intelectuales es que mientras los primeros, al ser bienes escasos, no exclusivos y rivales, necesitan de reglas colectivas que eviten la sobreexplotación del recurso, en el caso de los segundos, que previamente a su apropiabilidad podían considerarse bienes públicos puros, ocurre lo contrario: son bienes no rivales, donde el uso por parte de uno no afecta el de otros, sino que tiende a aumentar su circulación y su valor, y donde, desde el punto de vista de lo común, lo que hay que impedir es la rarefacción del recurso, que se hace de manera artificial, mediante la extensión de derechos de propiedad, de acceso, patentes, encriptaciones, etc. Esto es precisamente lo que lleva a Boyle y otros a hablar de new enclosures (Dardot y Laval, 2015: 184).

En efecto, una vez producidos, los bienes intelectuales pueden ser difundidos a un costo marginal casi nulo (Rifkin, 2014), especialmente con el avance de internet y de las tecnologías digitales, expandiéndose a nuevos terrenos. Por ejemplo, un programa informático, un libro o un archivo de música pueden ser compartidos en la red y utilizados sin generar costos adicionales y sin destruir el objeto en cuestión, como supone la tradicional noción de consumo. Por otro lado, cuanto más se comparte un conocimiento, una obra científica o artística, y mayor es la comunidad en torno suyo, más valor tiene (the more, the merrier). El conocimiento, expresado en ideas, se revela como un bien productivo, ya que su uso por parte de unos no disminuye el saber de los otros $\mathrm{y}$, favoreciendo la producción de nuevos conocimientos, permite aumentarlos (Dardot y Laval, 2015: 184). Al respecto, se suele citar la carta de Thomas Jefferson a Isaac Macpherson del 13 de Agosto de 1813, donde expresaba sus dudas acerca de la conveniencia de las patentes y afirmaba cosas como: "Quien recibe de mí una idea, recibe un conocimiento sin disminuir el mío, de la misma manera que quien enciende su vela con la mía, recibe luz sin dejarme a oscuras". ${ }^{4}$

Sin embargo, al igual que con los bienes materiales, no es la naturaleza del conocimiento lo que lo hace productivo o compartido sino las reglas jurídicas y sociales que garantizan o no su extensión y fecundidad (Dardot y Laval, 2015: 185), como así también los medios técnicos disponibles para su reproducción, conservación y difusión. Si el conocimiento debe ser considerado un bien común es porque ha dejado de ser un bien público (al ser capturado por las nuevas tecnologías digitales de copyright, etc.) y es necesario establecer reglas que permitan su renovación y mantenimiento, puesto que, así como las tecnologías disponibles hacen posible una mayor apertura y difusión, también producen nuevas formas de cercamientos. Son precisamente estos comunes los que están más sujetos a la mercantilización en la actualidad.

Por eso mismo, en el ámbito intelectual, el concepto de los comunes es frecuentemente un grito de batalla a favor de la libertad de expresión, acceso abierto universal y autogobierno (Hess y Ostrom, 2006: 29). En ese marco, se destacó el movimiento del software libre, relacionado con la ética hacker, y la defensa de la neutralidad de los protocolos de intercambios de datos en internet como movimientos por la defensa de los comunes, en los que la arquitectura de las redes es tan importante como las reglas jurídicas que buscan regularlas ex post (Lessig, 2000). 
Al mismo tiempo, el común aparece como un sector de creación de valor alternativo al mercado, por ejemplo a través de la cooperación en internet, sector que Benkler y Nissenbaum (2006) llaman de producción entre pares basada en el común: un sistema de producción radicalmente descentralizado, colaborativo y no propietario basado en compartir recursos y productos entre individuos distribuidos ampliamente y conectados laxamente que cooperan entre sí sin basarse ni en las señales del mercado ni en directivas manageriales. Benkler incluso toma al pingüino de Linux como símbolo de una antropología empática y cooperativa, que se opone tanto al Leviatán de Hobbes como a la mano invisible de Simth, que expresan al individuo egoísta y aislado como constitutivos del Estado y la economía liberales. A su vez, considera a internet como una herramienta que permitió llevar el comportamiento colaborativo al centro de la escena, en detrimento de las acciones que responden sólo al autointerés (Benkler, 2011).

En ese contexto, parte de estos comunes intelectuales refieren a las comunidades virtuales, donde los individuos pueden colaborar e interrelacionarse en base a intereses compartidos, sin tener que compartir vínculos sociales densos o una institución burocrática que gestione la cooperación. Sin embargo, no todos los teóricos ven esta cooperación descentralizada con el optimismo de Benkler o Rifkin. Para Rendueles y Sábada, este tipo de ideas son como

si las normas compartidas que sustentaban las instituciones que regulaban los bienes comunes pudieran sustituirse por protocolos técnicos. Es seguramente una aspiración excesiva que (...) concede demasiado al neoliberalismo y establece alianzas monstruosas entre la crítica antiinstitucional antagonista y los intereses de clase de las élites económicas y políticas. (2015: 44).

Ejemplo de ello sería el crowdfounding, tan celebrado como método para la financiación de proyectos de todo tipo, desde intervenciones artísticas a recolección de fondos para tratamiento de enfermedades. Si bien esto permite colaborar con proyectos que de otro modo difícilmente verían la luz, ello se da bajo el paradigma del emprendedorismo reinante, donde todos estaríamos igualados por la capacidad de emprender, y supone, en casos como el de la salud, una transferencia de las obligaciones del Estado hacia los individuos. (Rendueles y Sábada, 2015: 46).

Por otra parte, esta configuración de los comunes del conocimiento o de la información no se detienen en el terreno de lo inmaterial, como es el caso paradigmático del movimiento de software libre y acceso abierto que ha mostrado las potencialidades de estos comunes informáticos, sino que se extiende al internet de las cosas y a todo el sector de la economía colaborativa, donde surgen nuevas prácticas de producción y consumo que se realizan en común y donde el costo marginal de cada unidad que se agrega se acerca a cero (Rifkin, 2014). Ejemplo de ello serían los productos realizados en impresoras 3D en maker-spaces, fab labs, etc. en los que el capital fijo tiene un costo muy bajo de inversión y donde se pueden producir nuevos implementos gastando sólo en el material que se usa para imprimir. Otros ejemplos serían las nuevas redes de producción y distribución de 
energía producida de manera sustentable por los propios usuarios, es decir, prácticas como el car sharing, car pooling, bike sharing, que hacen, caeteris paribus, del transporte algo más sustentable ecológica y económicamente, o el couchsurfing, donde se expande la gratuidad al terreno del alojamiento, etc. Todo ello lleva a Rifkin (2014) a augurar el advenimiento de una sociedad donde los bienes producidos e intercambiados con fines de lucro irán perdiendo importancia frente a la economía colaborativa y donde el acceso reemplaza definitivamente a la propiedad individual, como en la perspectiva de Hardt y Negri (2011), el modelo de internet, una red descentralizada, horizontal y colaborativa, proveería el modelo organizacional de la sociedad post-capitalista basada en lo común.

Sin embargo, perspectivas como la de Rifkin adolecen de una suerte de determinismo tecnológico, como si el avance de las fuerzas productivas fuese la condición necesaria y suficiente para un cambio en las relaciones de producción, distribución y consumo. Todo ello se da en el marco de una escasa consideración de las relaciones de poder propias del capitalismo neoliberal y, en ese marco, del carácter no neutral de las tecnologías digitales. Dicho de otro modo, si bien como lógica abstracta el acceso parece más sustentable y equitativo que la propiedad, también es cierto que para cada vez más trabajadores el acceso es la única opción frente a la imposibilidad de ser propietarios. Es decir que la era del acceso coincide con la de un capitalismo cada vez más desigual, en el que los derechos sociales y el bienestar económico de su etapa gloriosa son reemplazados por el endeudamiento generalizado y la precariedad económica y existencial (Lazzarato, 2013). En este sentido, el car sharing, con todas sus virtudes posibles -como la descongestión del tránsito, menor contaminación, mejor utilización del espacio urbano, etc.- oculta mal el hecho de que mientras algunos reducen su huella ecológica, de manera forzada o voluntaria, otros la incrementan exponencialmente, $\mathrm{y}$, al mismo tiempo, que comprar y mantener un auto se ha vuelto imposible para muchos trabajadores del precariado actual, y se combina bien con la flexibilidad necesaria hoy en cuanto a horarios, posibilidad de trasladarse, etc., lo que contrasta claramente con la etapa keynesiana y fordista del capitalismo. En ese sentido, Morozov (2014) señala que la economía colaborativa puede ser un buen instrumento para lidiar con las consecuencias de la crisis económica y financiera, pero no puede atacar sus causas. ${ }^{5}$ Una crisis que, según Dardot y Laval, se ha vuelto un modo de gobernar (2016: 29 y ss).

En este sentido, a partir del análisis de los bienes comunes materiales y del conocimiento, nos parece evidente que la tragedia de los comunes no puede ser entendida como un resultado necesario de la acción racional, sino que describiría más bien un proceso histórico real, y aún vigente, de expropiación violenta de los comunes, o lo que Marx llamara acumulación originaria.

\section{La tragedia de los comunes revisitada: de la acumulación originaria a los nuevos cercamientos}

Como señalábamos, a diferencia de lo que podría sugerir el relato de Hardin, la tragedia de los comunes que dio origen al capitalismo en Inglaterra no fue pro- 
ducto de la avidez egoísta de los commoners sino de la expropiación de estos por parte de los terratenientes que, con el apoyo de la violencia material y luego legal del Estado, expropiaron a los campesinos de las tierras de labranza y llenaron la campiña inglesa de ovejas, desplazando a los trabajadores rurales a las ciudades. Este proceso es el que Marx designa con el nombre de acumulación originaria, caracterizada en El Capital (lib. I, sec. VII, cap. 24) como "prehistoria" del capitalismo. Aparece esbozada ya en su defensa del derecho consuetudinario de los pobres a recolectar leña en Renania en el marco del debate parlamentario que tuvo lugar entonces, publicada en 1842 en la Rheinische Zeitung. Allí, Marx explica la diferente naturaleza jurídica de la recolección de leña caída (que ya no pertenece al árbol y por ende tampoco a su propietario) respecto de la tala de un árbol en pie y de la sustracción de leña ya cortada, basándose en la distinta índole de la acción, la intencionalidad y la lesión que produce al propietario en cada caso. Declarando la recolección de leña suelta de un campo privado -una práctica habitual para la subsistencia y un derecho consuetudinario- como un delito, se impide acceder a los pobres a elementos esenciales para su subsistencia, que ahora deberán adquirir en el mercado. Este es un ejemplo claro del modo en que se transforman bienes de uso común en mercancías y a la propiedad privada en un derecho absoluto y exclusivo de los individuos, en detrimento de las formas subsistentes de propiedad comunal o "formas híbridas" de propiedad.

En El Capital, Marx se refiere de manera más sistemática a la acumulación originaria como el presupuesto de la acumulación capitalista, desempeñando en economía política el papel que tiene el pecado original en teología. El análisis marxiano se basa en el movimiento de cercamientos que hizo posible la expulsión del campesinado inglés a las ciudades y su transformación en obreros industriales urbanos, dando lugar al moderno proletariado. "La llamada acumulación originaria no es, pues, más que el proceso histórico de disociación entre el productor y los medios de producción" (Marx, 1974: 103). Para el autor, dicho proceso tiene en su génesis la violencia en forma de conquista, robo, colonización, asesinato, etc. Marx sitúa alrededor de 1750 la desaparición de los campesinos independientes y luego la eliminación de los últimos vestigios de propiedad comunal de los braceros, proceso paralelo al saqueo y usurpación de los bienes de dominio público (Ibidem). El despojo de los bienes comunales tuvo como forma parlamentaria "la de los Bills for Inclosures of Commons (leyes sobre el cercado de terrenos comunales) (...) decretos por medio de los cuales los terratenientes se regalan a sí mismos en propiedad privada las tierras del pueblo" (Ibidem: 113). Dicho proceso de expropiación llega a su término con el Clearing of Estates, es decir, la expulsión lisa y llana de los seres humanos que quedaban en esas fincas, que tuvo sus formas más dramáticas en las tierras altas escocesas en las que los jefes de los clanes se quedaron con la propiedad exclusiva de las tierras comunales y expulsaron de ellas a sus compatriotas. Marx resume el proceso descrito de la siguiente forma:

La depredación de los bienes de la Iglesia, la enajenación fraudulenta de las tierras del dominio público, el saqueo de los terrenos comunales, la metamorfosis, llevada a cabo por la usurpación y el terrorismo más 
inhumanos, de la propiedad feudal y del patrimonio del clan en la moderna propiedad privada: he ahí otros tantos métodos idílicos de la acumulación originaria. Con estos métodos se abrió paso a la agricultura capitalista, se incorporó el capital a la tierra y se crearon los contingentes de proletarios libres y privados de medios de vida que necesitaba la industria de las ciudades (Ibídem: 121-122).

En efecto, el movimiento de enclosures es un gran hito en la privatización de los comunes que, entre los siglos XVI y XIX, eliminara los derechos de uso consuetudinarios de los pobres en Europa sobre determinadas tierras y sus frutos, considerados propiedad común, y gestionados por formas de autogobierno. Con el cercamiento los commons, junto con la legislación que reprimía el vagabundaje y el hurto con penas sanguinarias, los campesinos fueron transformándose progresivamente en el moderno proletariado, elemento subjetivo sin el cual no hubiese sido posible el capitalismo industrial. ${ }^{6}$

Cabe resaltar aquí el doble sentido de los commons tradicionales: por un lado, los bienes comunes o comunales en sentido material y jurídico -res comunes, que no deben ser confundidas con las res nullius-; por otro, las instituciones políticas de los plebeyos, los comunes donde se tomaban decisiones sobre el autogobierno local. Cabe agregar a esto que common remite asimismo desde el siglo XIV al cuerpo parlamentario que representa al tercer Estado (la House of Commons).

De allí la necesidad de ocuparnos nuevamente de los comunes, no para idealizar un pasado precapitalista, sino para comprender lo que se juega en la tensión entre producción de lo común y cercamientos. En este sentido, Ibañez y de Castro (2015) sostienen que:

la gestión de recursos comunes no es una cuestión de eficiencia económica, es obviamente una cuestión social y política. Los cercamientos parlamentarios en Inglaterra no sólo buscaban una destrucción económica de la comunidad (a través de la universalización y homogeneización de la propiedad privada individual), sino que reflejan, tal y como demostró E. P. Thompson, una lucha política por destruir su autonomía y su capacidad de autogestión de los recursos (es decir, sus órganos de representación, sus instituciones formales e informales, su cultura, sus valores $[\ldots]$ sus prácticas).

Este proceso, que Marx sitúa en la prehistoria del capitalismo, aparece interpretado en la actualidad como un proceso que retorna constantemente, no sólo en términos de acaparamientos de tierras (land grabbing) y recursos naturales de distinto tipo (Dardot y Laval, 2015: 115), con la consiguiente expulsión de población campesina -que sigue siendo un proceso en curso en África, Asia y América latina y que ha llevado recientemente a que la mayoría de la población mundial habite en ciudades- sino en la extensión de los cercamientos a nuevos terrenos. En este sentido, Mezzadra y Gago señalan: 
Mientras que el análisis de Karl Marx se concentraba en el momento de la transición hacia el capitalismo, el uso contemporáneo de la categoría misma de acumulación originaria se refiere a transiciones en el interior del capitalismo y, más en general, a momentos constitutivos del accionar del capital. Cercamientos, violencia extraeconómica, apertura del mercado mundial: estos procesos destacados por Marx como característicos de la acumulación originaria se representan de forma distinta en el momento en que el problema ya no es la "colonización" de espacios geográficos y sociales no capitalistas, sino la violenta reorganización de espacios y sociedades ya sumidos a la lógica de la valorización capitalista (2015: 48).

Precisamente porque las modalidades de expropiación descritas por Marx hablan todavía en parte del presente capitalista, Harvey (2005: 27) prefiere hablar de acumulación por desposesión. Este último concepto remitiría a un tipo de acumulación distinto al de la explotación propiamente dicha - es decir, a la extracción de plusvalía mediante la subsunción real del trabajo al capital-, puesto que se vale de medios fundamentalmente políticos, jurídicos, económicos e incluso militares que permiten a la clase dominante apropiarse de lo que hasta entonces no era propiedad de nadie, o bien era propiedad pública o colectiva. Para Harvey, este tipo de acumulación consiste fundamentalmente en la privatización y mercantilización de aquello que estaba por fuera de las lógicas mercantiles, utilizando formas de coacción extraeconómicas, como la violencia material y las reglas jurídicas. Este tipo de acumulación se volvería hegemónica con el capitalismo financiero y daría cuenta de esta nueva ola de cercamientos que, con el neoliberalismo, se extiende a nuevos terrenos, pues no sólo abarcaría a los bienes comunes naturales sino también a los culturales o intelectuales. Por lo demás, la financiarización sirve como un instrumento de desposesión a través de la trampa de la deuda (Harvey, 2007).

En ese sentido, cabe destacar el carácter pionero que tuvo el colectivo y revista estadounidense Midnight Notes, que dedica su décimo número, de 1990, al tema New Enclosures. En su editorial, los autores señalan que en la década del '80 se asistió al mayor cercamiento de lo común mundano (worldly common) en la historia.

Los cercamientos no son un proceso agotado en los albores del capitalismo sino algo que retorna regularmente en el camino de la acumulación y un componente estructural de la lucha de clases. Cada salto en el poder proletario demanda una respuesta capitalista dinámica: tanto la apropiación expandida de nuevos recursos y nueva fuerza laboral como la extensión de las relaciones capitalistas. De lo contrario, el capitalismo es amenazado con su extinción (1990: 1).

Las razones por las cuales los cercamientos pasan a ser la experiencia común del proletariado en todo el mundo, dando lugar a la mayor diáspora y a la fuerza laboral más móvil de la historia, son identificadas en las conquistas de los trabajadores que, entre los años 1965 y 1975, pusieron en crisis al capitalismo: eso mismo 
que las ciencias sociales hegemónicas calificaban por entonces como sobrecarga de demandas y los think tanks neoliberales llamaban un exceso de democracia. La respuesta a ello fueron las políticas neoliberales que permitieron poner a competir a la mano de obra a escala mundial y asestar un golpe durísimo a la clase trabajadora de las distintas naciones, cercenando los derechos sociales y laborales conquistados hasta el momento.

En ese marco, por ejemplo, en África y América latina, los programas de endeudamiento y ajuste estructural llevaron a la expulsión de los campesinos de sus tierras comunales para producir commodities, y a la desmonetarización de las economías vía devaluaciones masivas. Para los editores, la "crisis de la deuda", la "carencia de hogar [homelessness]" y "el colapso del socialismo" forman parte de un único proceso de cercamientos. "Con cada contracción de los "derechos comunales' en el Tercer Mundo o de 'derechos socialistas' en la Unión Soviética y China viene una sustracción de nuestros aparentemente sagrados 'derechos sociales' en Estados Unidos" (1990: 2). Los nuevos cercamientos nombrarían

la reorganización a gran escala del proceso de acumulación que ha estado en marcha desde mediados de los '70. El principal objetivo de este proceso ha sido desarraigar a los trabajadores del terreno en el cual su poder organizacional ha sido construido, de modo de (...) ser forzados a trabajar y pelear en un ambiente extraño en el cual las formas de resistencia posibles en casa ya no están disponibles. Así, nuevamente, como en los albores del capitalismo, la fisonomía del proletariado mundial es la del indigente [pauper], el vagabundo, el criminal, el pordiosero [panhandler], el vendedor ambulante, el refugiado que trabaja en un taller clandestino, el mercenario, el agitador (1990: 3).

Al igual que los viejos cercamientos, los nuevos operarían poniendo fin al control comunal de los medios de subsistencia. Por ejemplo, apropiándose de tierras a través de las deudas. Por otra parte, al generar la expulsión de campesinos de sus tierras, hacen del trabajo migrante la forma dominante de trabajo, lo cual garantiza bajos salarios, desorganización comunal y vulnerabilidad frente a las autoridades. Por eso fue decisivo el colapso del bloque socialista, pues permitió que toda esa mano de obra entrase a competir entre sí y se expandiera el mercado laboral a nivel global. Por lo demás, los nuevos cercamientos atacan nuestra reproducción, haciéndonos mutantes a la vez que migrantes, con la destrucción de los comunes terrestres (nuestro hábitat) y el avance de las biotecnologías, que, entre otras cosas, nos obligan a alimentarnos de organismos modificados genéticamente. Ello sin contar otras transformaciones que hacen al mundo del trabajo, donde los trabajadores de algunos servicios deben modificar sus cuerpos para cumplir con las demandas del mercado (Midnight Notes, 1990).

Uno de los intelectuales que se ha referido a estos nuevos enclosures es David Bollier, quien sostiene que las grandes compañías están privatizando recursos valiosos de los comunes y que una vez que ya no son rentables, las corporaciones tiran sus desechos y disrupciones sociales (conocidas como externalidades) de 
vuelta a los comunes, trasladándoles el problema al gobierno y a los commoners. Este autor define los cercamientos de manera muy simple: "Cercamiento significa que la gente tiene que empezar a pagar por recursos a los que anteriormente accedía gratuitamente o de manera económica. Significa que la gente necesita pedir permiso para usar algo que antes era suyo por derecho" (Bollier, 2007: 11).

En esta segunda ola de cercamientos, a la privatización o sobreexplotación de recursos naturales no renovables se suma la privatización de servicios, como la salud, la educación, el acceso a la vivienda, y de los bienes inmateriales, como el patrimonio cultural y científico, especialmente con la extensión de los regímenes de patentes y derechos de autor al área del conocimiento, la información e incluso de la vida. Estos cercamientos se dan a través de leyes de copyright, patentes, etc. que generan derechos de propiedad exclusivos sobre bienes que por sus propias características son no-rivales, poniendo obstáculos a la circulación del conocimiento, a la innovación y a la libertad de expresión. Los derechos de propiedad intelectual han permitido no sólo extender los alcances temporales del copyright, sino incluso patentar información genética, que hasta los años ' 80 era entendida como no patentable por no ser los genes obra del ingenio humano. Gracias a esta posibilidad de patentar formas vivientes, hemos asistido a un incremento exponencial del poder de las empresas multinacionales de biotecnología, que no sólo han creado tecnologías tendientes a monopolizar sus mercados y controlar así la producción de alimentos a escala mundial, sino también a formas de biopiratería (Shiva, 2002), consistente en el patentamiento por parte de empresas transnacionales de saberes autóctonos milenarios y de productos asociados a ellos, produciendo biocapital y biovalor (Shand, 2003; Sunder Rajan, 2006; Sacchi, 2013; Dardot y Laval, 2015) y poniendo en riesgo la biodiversidad y la soberanía alimentaria de diversas naciones. En este sentido, la extensión de las patentes y de los derechos de propiedad intelectual a los recursos genéticos y vivientes representa un verdadero cercamiento o privatización de los bienes comunes biológicos e intelectuales, posibilitado por la ausencia de un marco legal que proteja la integridad de los sistemas de saber indígenas (Shiva, 2002) a los que el derecho internacional vigente considera como parte de la "naturaleza" y no del "ingenio humano". Este movimiento de cercamientos puede definirse como "una dinámica global y difusa de expropiación de recursos comunes con la consiguiente transferencia de prerrogativas del dominio colectivo al del mercado" (Coccoli, 2013: 14).

Como decíamos, esto mismo se verifica con la extensión del tiempo de los derechos de autor para las creaciones artísticas y las obras científicas, la información académica y los medios digitales. De allí la ambivalencia de las nuevas tecnologías, ya que pueden potenciar los comunes o hacerlos más vulnerables. Como señalan Hess y Ostrom (2006), las nuevas tecnologías pueden permitir la captura de lo que habían sido bienes públicos abiertos y gratuitos. Esto sucedió con el desarrollo de la mayoría de los "comunes globales", como los mares, la atmósfera, el espectro electromagnético o el espacio.

Esta capacidad de capturar lo previamente incapturable produce un cambio fundamental en la naturaleza del recurso, siendo éste convertido 
de un bien público no-rival y no-exclusivo en un recurso de uso compartido que necesita ser administrado, monitoreado y protegido para asegurar la sustentabilidad y la preservación (Hess y Ostrom, 2006: 25).

Por otro lado, con los bienes comunes intelectuales se abren nuevas posibilidades para el acceso abierto universal, el autogobierno y la libertad de expresión. Incluso permiten transformar en comunes ciertos bienes o servicios que anteriormente era imposible o muy difícil compartir y producir en conjunto de manera remota y descentralizada, como sucede con el software libre, que "ha mostrado de manera espectacular que el común es una alternativa viable a la mercantilización [commodification]" (Hess y Ostrom, 2006). Esto no quiere decir que haya que identificar a los comunes con el Open Access. En ese sentido, las autoras recuperan la distinción que hace Levine entre un común libertario, al que cualquiera puede acceder si lo desea, y los comunes asociativos, que están abiertos a sus miembros pero pueden no estar abiertos al público en general.

En ese marco, para Coriat, los comunes de hoy, en lucha contra los enclosures del pensamiento y la creación constituidos por los derechos de propiedad intelectual, serían herederos de las luchas contra los enclosures físicos del pasado (Coriat, 2015). ${ }^{7}$ De hecho, la alianza entre empresas multinacionales y gobiernos en torno a los derechos de propiedad intelectual ha despertado como contrapartida el movimiento de los comunes (Dardot y Laval, 2015: 133). En este sentido, V. Shiva (2002) señala que "si la globalización es el enclosure final de los comunes [nuestra agua, biodiversidad, cultura, salud, alimentos, educación, etc.] recuperar los comunes es el deber político, económico y ecológico de nuestra época". ${ }^{8}$

En esa dirección es que los editores de Midnight Notes señalaban que estos cercamientos han hecho que los trabajadores de hoy sean mucho más conscientes de la composición de clase a nivel internacional, han obligado a un internacionalismo de la acción proletaria, y la necesidad de organizar la reproducción fuera de la relación monetaria ha forzado frecuentemente a los trabajadores a desarrollar su autonomía en las esferas de la producción y la reproducción.

En un texto más reciente, en medio de la crisis financiera que asoló a Estados Unidos en 2008-2009, este análisis de los enclosures se actualiza, donde los cercamientos se producen centralmente sobre los comunes del ecosistema y del trabajo acumulado a través de la historia. Los autores proponen reapropiarse de esos comunes y adoptar una perspectiva constitucional que decida cómo compartir los recursos comunes, porque un común (a commons) sin una comunidad conscientemente constituida es impensable (Midnight notes, 2009: 11). En términos negrianos, las condiciones del capitalismo actual hacen posible el surgimiento de una nueva multitud en lucha por la constitución y defensa de los comunes, tanto del mundo físico como del conocimiento.

En efecto, para Hardt y Negri asistimos a una producción biopolítica que se basa enteramente en lo común, tanto en términos de bienes materiales como de todo aquello que es producto y a la vez condición de posibilidad de la cooperación social, como lenguajes, códigos, afectos, relaciones, etc., y es el valor producido 
de manera autónoma el que es capturado desde fuera por diversas formas de renta, en las que destaca el capital accionario. Sin embargo, la idea de una exterioridad entre cooperación social productiva de valor y dirección capitalista, que aparece de manera más o menos clara en el terreno de la informática, debe ser matizada en lo que refiere a la sociedad en general. En ese sentido, Gago y Mezzadra señalan que, aunque los capitalistas no organicen directamente la cooperación de los sujetos, dicha cooperación dista de ser libre. Cuando Facebook extrae valor de nuestros datos e interacciones en la red, lo hace guiándonos con sus algoritmos, de la misma manera que las finanzas populares se desarrollan bajo el signo de la deuda (Gago y Mezzadra, 2015: 255).

Por eso mismo, Mezzadra sostiene que hay que asumir que los comunes no son algo dado sino producido colectivamente y que, por ello, se trata de que un sujeto colectivo lo produzca y sea capaz de destruir "las bases de la explotación y de reinventar las condiciones comunes de una producción estructurada en base a la síntesis de libertad e igualdad" (2008).

\section{A modo de cierre: lo común como principio de acción política}

A lo largo de este trabajo intentamos mostrar que la teoría formal de la tragedia de los comunes se ve refutada tanto en el propio terreno de la elección racional como por los procesos históricos que derivaron y derivan en la destrucción de los comunes materiales. En ese marco, nos detuvimos en los aportes fundamentales de Ostrom, Hess, y Feeny, que establecieron desde los años '80 una clara distinción entre los bienes de acceso abierto y los bienes comunes, y que descartaron el modelo del dilema del prisionero y los supuestos de una maximización de intereses egoístas utilizado por Hardin para entender el funcionamiento de los comunes. No se trataba de negar la existencia de intereses particulares, sino de mostrar que, si se tienen en cuenta los arreglos institucionales que los agentes sociales pueden realizar, los comunes pueden ser exitosamente gestionados por quienes están interesados en su conservación en el tiempo y en su proliferación. Esto vale tanto para los comunes tradicionales como para los nuevos comunes del conocimiento, donde son decisivas las reglas jurídicas en torno a la propiedad y sus usos posibles.

Autores contemporáneos, como Dardot y Laval, buscan extender los alcances de estas teorías, entendiendo a lo común como un principio de acción política según el cual existe una co-obligación entre quienes participan en la producción y mantenimiento institucional de los comunes. En ese sentido, mostraban que los análisis de Ostrom representan un gran avance teórico, al introducir una perspectiva gubernamental de los bienes comunes, pero que, al mismo tiempo, en su afán de precisión metodológica y cierto grado de epojé axiológica, la perspectiva de Ostrom se mostraría insuficiente para pensar las potencialidades políticas que se pueden extraer de una revitalización de los comunes en términos anticapitalistas. Como señalan Ibañez y de Castro, los análisis de Ostrom tienen la virtud de la formalización teórica y la precisión conceptual en referencia a los bienes de uso común, mostrando cuáles serían los requisitos institucionales para una gestión 
exitosa de éstos. Sin embargo, ello se pagaría al precio de

reducir la alternativa de la gestión común a los huecos que la economía capitalista decida ir dejando libres. Pues aquí "los comunes" dejan de ser un fenómeno social total, que requiere de un entramado social y político propio (por tanto, necesariamente conflictivo con la lógica dominante), para pasar a ser una gestión económica alternativa de determinados recursos (Ibáñez y de Castro, 2015: 10).

En ese sentido, Méndez de Andés, del Observatorio Metropolitano de Madrid, señala que los comunes deben ser leídos políticamente, puesto que se definen colectivamente, y están formados por

el propio recurso (material o inmaterial), la comunidad de sujetos que generan y sostienen la producción y reproducción del recurso y el modo de gestión, como marco normativo, sea reglado o no reglado. Ninguno de estos elementos está dado, sino que se alimentan mutuamente en un proceso de devenir-común (2015: 33).

En ese marco, establece cuatro premisas fundamentales en la gestión colectiva de los recursos comunes: universalidad de acceso para toda la comunidad a cargo del recurso; sostenibilidad, "para que puedan ser disfrutados por las generaciones futuras"; democracia para la gestión y las decisiones sobre accesibilidad y sostenibilidad del recurso; inalienabilidad: "los recursos comunes no se pueden vender en el mercado, especular con ellos ni acumular con vistas a beneficios futuros. $\mathrm{Su}$ valor es el valor de uso y, de esta forma, se escapan a la lógica del mercado financiero" (Ibidem).

En un sentido similar, David Bollier señala que la política de los comunes incluye una gran diversidad de campos de disputa y de actores sociales, desde las comunidades que defienden el acceso al agua hasta quienes contribuyen a la creación de software libre. En ese marco, define a los comunes como un término genérico para describir todo aquello que heredamos de la naturaleza y la sociedad civil y tenemos el deber de transmitir de manera intacta a las futuras generaciones. "Un común emerge cuando una comunidad decide que quiere gestionar un recurso colectivamente, con especial cuidado por el acceso equitativo, el uso y la sostenibilidad" (Bollier, 2007: 11).

Esto implica ir más allá de las definiciones de Ostrom, hacia una perspectiva política e incluso normativa de los comunes, como principio alternativo a la racionalidad neoliberal y capitalista, basadas en el individualismo propietario y la competencia empresarial. Por eso insistimos en señalar que la debacle de los comunes no obedece a la incompatibilidad de su gestión con una naturaleza humana egoísta o con el ineluctable avance de las fuerzas productivas, sino que ha sido y es parte de la victoria política de quienes han sostenido la voluntad de que el mundo quede repartido entre la propiedad privada del individuo y la propiedad pública, entre la gestión empresarial y la estatal, que, lejos de solucionar las tragedias de los comunes, las han producido. 
En este sentido, la hipótesis de los cercamientos es siempre política, porque hace necesaria la intervención de factores ajenos a cualquier idea de autorregulación productiva, como son la violencia material y la coacción jurídica, que buscan ocultarse detrás de una ideología que considera a la propiedad privada como el derecho más importante y piedra basal de la sociedad, junto con la gestión privada como la más eficiente. Sin embargo, es evidente que el objetivo principal de las empresas privadas que gestionan los recursos comunes es maximizar sus ganancias, lo cual en la actualidad entra en contradicción con las posibilidades de reproducción de la vida en nuestro planeta finito. La guerra del agua en Cochabamba fue un ejemplo claro de dicha contradicción, en la cual la voracidad de las empresas puso en riesgo la reproducción de la vida económica y social. Desde entonces, desde La Paz a Nápoles, pasando por París, Grenoble y tantas otras ciudades del mundo, avanzan las experiencias de cogestión del agua entre la comunidad y el gobierno, que resultan más eficientes y económicas que la gestión privada y que dan el control a las comunidades sobre sus propios recursos y entornos. No obstante, apostar por la gestión de los recursos por parte de los propios interesados no es sólo una apuesta por una alternativa técnicamente más eficaz que la gestión privada o estatal: es apostar políticamente por expandir el espacio de una cooperación social no sujeta a explotación, inventando e instituyendo prácticas que hagan posible la propiedad y la gestión colectivas de los recursos estratégicos para la reproducción de la vida social. Esto no implica necesariamente que el mercado y el Estado se vuelvan irrelevantes o desaparezcan.

Hoy existen problemáticas globales, como el cambio climático, en las que las políticas del común deberían ser acompañadas con el poder coercitivo de los Estados y organismos internacionales, fijando reglas claras para evitar la tragedia a la que lleva el comportamiento egoísta de los grandes contaminadores, que utilizan el común como un vertedero de desechos y toxinas. Pero no se trata sólo de evitar males sino de producir lo nuevo y, en esa tarea, ya no se puede confiar la gestión de nuestras vidas ni a las empresas privadas, que por su propia conformación buscan maximizar beneficios a cualquier precio, ni a un Estado que trabaja para garantizar la rentabilidad a dichas corporaciones, autonomizándose totalmente de los intereses de las mayorías.

De allí la importancia de la autonomía política de los commoners. No sólo porque la clase obrera organizada, con capacidad de influencia sobre lo público y sobre el mercado, ha dejado de cuestionar hace tiempo al orden dominante, sino también porque, frente a una representación política comprometida hasta la médula con el sistema de poder vigente, el futuro de la humanidad dependerá de la capacidad de construir nuevas formas de autogobierno y una gestión sustentable ecológica y socialmente de los recursos compartidos, es decir: la capacidad de decidir en común sobre el propio destino. No se trata de recuperar formas pretéritas de comunismo, porque no hay armonía alguna que reencontrar, sino de construir nuevas instituciones del común, que permitan ir modificando nuestras sociedades y generando espacios de producción y reproducción ajenos al mercado capitalista. Seguramente es poco probable, más allá de las experiencias que surgen en distin- 
tos lugares, que las instituciones de los comunes locales puedan modificar radicalmente la sociedad, pero es necesaria una acción política y social que muestre un camino alternativo, ante la destrucción acelerada a la que se ve sometido nuestro planeta por la ilimitación de la acumulación y la desmesura del consumo.

\section{Referencias}

1. Hardin reconoce como antecedente de su posición las ideas de Lloyd (1968) en la década de 1830. También se señalan como antecedentes inmediatos, aunque no citados por Hardin, dos textos que toman como casos de análisis las pesquerías: J. S. Gordon (1954) y A. D. Scott (1955).

2. Estos supuestos teóricos serían reforzados por corrientes como el neo-institucionalismo de North y Thomas, quienes consideran que la clave del crecimiento económico registrado en Occidente se debe a los dispositivos institucionales que favorecieron el enriquecimiento personal. Los individuos se verían impulsados a actuar, a innovar, a producir, sólo en vistas de obtener un beneficio material, una utilidad, como sucede, por ejemplo, con la posibilidad de patentar un producto determinado. Como señalan Dardot y Laval (2015), este tipo de teorías coincidieron con un momento histórico en que se extendían las patentes a nuevos dominios y se reforzaba su duración y alcance, dando lugar al conflicto entre los comunes y la propiedad intelectual (vid. Infra).

3. "Aparte de la propiedad privada individual, la legislación de propiedad del siglo XIX, tanto en Gran Bretaña como en Estados Unidos (...) reconocía dos tipos distinguibles de propiedad pública. Una de estas era propiedad 'poseída' y gestionada activamente por un cuerpo gubernamental. La otra, sin embargo, era propiedad 'poseída' y 'gestionada' colectivamente por la sociedad en su conjunto, que se reivindica independiente de, e incluso superior a las reivindicaciones de cualquier pretendido gestor gubernamental. Es este último tipo el que llamo "propiedad inherentemente pública"' (Rose, 1986: 720). En este caso, como en el resto de la bibliografía citada en otros idiomas, la traducción es propia. 4. The Founders' Constitution, Volume 3, Article 1, Section 8, Clause 8, Document 12, The University of Chicago Press, disponible en: http://press-pubs.uchicago.edu/founders/documents/a1_8_8s12.html, traducción propia.

5. El bielorruso señala en una nota periodística que "el gran problema de estos relatos optimistas y utópicos (...) es que racionalizan las patologías del actual sistema político y económico, presentándolas como opciones vitales conscientes. Está bien poder elegir entre alquilar o poseer, pero mucha gente debe conformarse con 'alquilar'. Ante el enorme desempleo juvenil, el estancamiento de la renta y los estratosféricos precios inmobiliarios, la economía colaborativa actual funciona como una especie de varita mágica. Los que ya son propietarios de algo pueden sobrevivir convirtiendo su malestar en dinero (...). Los que no tienen posesiones, pueden disfrutar ocasionalmente de un atisbo de buena vida: erigida por completo sobre bienes que no poseen. Igualmente risibles son los supuestos beneficios medioambientales de la economía colaborativa: mientras se nos pide que compartamos el coche con los vecinos — ¡es más barato y ecológico!-, los ricos siguen disfrutando de yates, limusinas y aviones privados, y los auténticos agentes contaminantes - las empresas petrolíferas y los gigantes del gas - se van de rositas después de cometer delitos aún peores. No cabe duda de que la economía colaborativa puede hacer más soportables las consecuencias de la actual crisis financiera (y probablemente lo haga). Sin embargo, al fijarse en las consecuencias, no hace nada para combatir las causas" (Morozov, 2014).

6. Como señalan Gago y Mezzadra (2015: 49), en la acumulación originaria se da la producción de subjetividad proletaria, que hoy adquiere nuevas formas irreductibles a la del proletariado industrial. Sin embargo, el relato marxiano aparece como incompleto al no considerar el rol de la economía esclavista, señalado por Moulier-Boutang, ni el sometimiento del cuerpo femenino mediante, erosionando sus lugares de poder y reconocimiento social, donde la caza de brujas, estudiada por Frederici, desempeñó un papel clave. Sobre esto se detienen Gago y Quiroga (2014).

7. De todos modos, como hemos visto, los enclosures físicos son parte de nuestro presente. No hay un orden de sucesión entre tipos de bienes comunes.

8. "Water democracy", apud Dardot y Laval (2015: 110). 


\section{Bibliografía}

Y. BENKLER (2011), The Penguin and the Leviathan: The Triumph of Cooperation Over Self-interest, New York, Crown Publishing.

Y. BENKLER y H. NISSENBAUM (2006), "Commons-based Peer Production and Virtue", en The Journal of Political Philosophy, 4 (14).

D. BOLLIER (2007), "A New Politics of the Commons", en Renewal: a Journal of Social Democracy, Vol $15, \mathrm{~N}^{\circ} 4$.

L. COCCOLI (2013), Commons. Beni comuni: il dibattito internazionale, (e-book), Florencia, goWare.

B. CORIAT (2015), “Qu'est ce qu'un commun ? Quelles perspectives le mouvement des communs ouvre-t-il à l'alternative sociale. Quatre thèses pour nourrir un débat en cours?", en Les Possibles, $\mathrm{N}^{\circ} 5$, Invierno. Disponible en : https://france.attac.org/nos-publications/les-possibles/numero-5-hiver-2015/ dossier-les-biens-communs/article/qu-est-ce-qu-un-commun.

P. DARDOT y Ch. LAVAL (2015), Común. Ensayo sobre la revolución en el siglo XXI, Barcelona, Gedisa.

P. DARDOT y Ch. LAVAL (2016), Ce cauchemar qui n'en finit pas. Comment le néolibéralisme défait la démocratie, Paris, La Découverte.

N. DOLSAK y E. OSTROM (2003), The Commons in the New Millennium: Challenges and Adaptation, Cambridge, MIT Press.

D. FEENY, F. BERKES, B. J. MCCAY and J. M.ACHESON (1990), "The Tragedy of the Commons: Twenty-Two Years Later", en Human Ecology 18 (1).

V. GAGO y N. QUIROGA DÍAZ (2014), "Los comunes en femenino. Cuerpo y Poder ante la expropiación de las Economías para la vida", en Economía y sociedad, Vol. 19, № 45. Disponible en: www. revistas.una.ac.cr/economia.

V. GAGO y S. MEZZADRA (2015), "Para una crítica de las operaciones extractivas del capital. Patrón de acumulación y luchas sociales en el tiempo de la financiarización”, en Nueva Sociedad, No. 255, enero-febrero.

G. HARDIN (1978), "Political Requirements for Preserving our Common Heritage", en H. P. BOKAW (ed.), Wildlife and America, Washington D.C., Council on Environmental Quality.

G. HARDIN (1995 [1968]), "La tragedia de los comunes", en Gaceta Ecológica, № 37, Instituto Nacional de Ecología, México. Disponible en: http://www.ine.gob.mx/.

M. HARDT y A. NEGRI (2011), Commonwealth. El proyecto de una revolución del común, Madrid, Akal.

D. HARVEY (2007), Breve historia del neoliberalismo, Madrid, Akal.

D. HARVEY (2005), "El nuevo imperialismo. Acumulación por desposesión”, en Herramienta, N ${ }^{\circ}$ 29, junio de 2005.

D. HARVEY (2011), “The Future of the Commons", en Radical History Review, Issue 109 (Winter 2011) doi 10.1215/01636545-2010-017.

C. HESS \& E. OSTROM (2006), "Introduction. An Overview of the Knowledge Commons",en C.

HESS y E. OSTROM (eds.), Understanding Knowledge as a Commons. From theory to Practice, Cambridge, MIT Press.

R. IBÁÑEZ y C. DE CASTRO (2015), "Los comunes en perspectiva: eficiencia versus emancipación", en Economistas sin fronteras, Dossier $N^{\circ} 16$, Madrid.

L. LESSIG (2000), "Code is Law. On Liberty in Cyberspace", en Harvard Magazine, 1/1/2000. Disponible en: http://harvardmagazine.com/2000/01/code-is-law-html.

M. LAZZARATO (2013), Il governo dell'uomo indebitato, Roma, DeriveApprodi.

K. MARX (1974 [1867]), "La llamada acumulación originaria. Cap. XXIV de El capital", en C. MARX y F. ENGELS, Obras Escogidas (III tomos), Tomo II, Moscú, Editorial Progreso.

A. MÉNDEZ DE ANDÉS (2015), "Las formas del común”, en Economistas sin fronteras, Dossier N 16, Madrid.

S. MEZZADRA (2008), "Attualità della preistoria. Per una rilettura del capitolo 24 del primo libro del Capitale, «La cosiddetta accumulazione originaria»”, en La condizione postcoloniale. Storia e politica nel presente globale, Verona, ombre corte. 
MIDNIGHT NOTES COLLECTIVE \& FRIENDS (2009), "Promissory Notes: From Crisis to Commons". Disponible en: http://www.midnightnotes.org/Promissory\%20Notes.pdf, consultado el $10 / 06 / 2016$.

MIDNIGHT NOTES COLLECTIVE (1990) “Introduction to The New Enclosures", Midnight Notes, 10 "The New Enclosures". Disponible en: http://www.midnightnotes.org/newenclos.html.

E. MOROZOV (2014), "La tecnología que nos aísla”, en El País, España. Disponible en: http://elpais. com/elpais/2014/10/03/opinion/1412336783_752251.html.

F. ORSI (2015), "Reconquérir la propriété : un enjeu déterminant pour l'avenir des communs", en Les Possibles, $\mathrm{N}^{\circ}$ 5, Invierno. Disponible en : https://france.attac.org/nos-publications/les-possibles/ numero-5-hiver-2015/dossier-les-biens-communs/article/qu-est-ce-qu-un-commun.

E. OSTROM (2011[1990]), El gobierno de los bienes comunes, México, Fondo de Cultura Económica.

C. RENDUELES e I. SÁBADA (2015), "Los bienes comunes en un entorno de fragilidad social: El caso del crowdfunding", Economistas sin fronteras, Dossier $N^{\circ} 16$, Madrid.

J. RIFKIN (2014), The zero marginal cost society: the internet of things, the collaborative commons, and the eclipse of capitalism, Nueva York, Palgrave - McMillan.

C. ROSE (1986), "The Comedy of the Commons: Commerce, Custom, and Inherently Public Property", en Faculty Scholarship Series. Paper 1828. Disponible en: http://digitalcommons.law.yale.edu/ fss papers/1828.

E. SACCHI (2013), Biopoliticas: del organismo a la información: Aportes para un diagnóstico sobre la biopolitica contemporánea a partir de las transformaciones en el orden saber-poder del siglo $X X$, Tesis de Doctorado, Facultad de Ciencias Sociales, Universidad de Buenos Aires.

H. SHAND (2003), "New Enclosures: Why Civil Society and Governments Need to Look Beyond Life Patenting", en CR: The New Centennial Review, 3 (2). Disponible en: http://www.jstor.org/ stable/41949392.

V. SHIVA (2002), "The Enclosure and Recovery of the Biological and Intellectual Commons", en D.K. MAROTHIA (ed.), Institutionalizing Common Pool Resources, Nueva Delhi, Concept Publishing Company.

K. SUNDER RAJAN (2006), Biocapital: The Constitution of Postgenomic Life, Durham, Duke University Press.

Recibido: 05/12/2016. Aceptado: 20/02/2017.

Matías L. Saidel, "La tragedia de los comunes revisitada: de la teoría formal a las formas históricas de desposesión". Revista Temas y Debates. ISSN 1666-0714, año 21, número 33, enero-junio 2017, pp. 163-184. 